\title{
IMPACT OF SUPPLIER EVALUATION ON PRODUCT QUALITY
}

\author{
Thais da C. L. Alves ${ }^{1}$, Panthil Desai ${ }^{2}$, Kim L. Needy ${ }^{3}$, Ashleigh Hegwood ${ }^{4}$, and Sean \\ Musick $^{5}$
}

\begin{abstract}
Supplier evaluation and engagement are regular topics in the Lean literature at large. It is well known that Toyota extensively works with suppliers to develop their work and capabilities, and provides challenges and feedback to suppliers so that they can achieve the quality requirements defined by the company. In the construction industry, companies conduct evaluations of suppliers, but practitioners cite numerous reasons why supplier evaluations are not constantly shared with suppliers. Moreover, the topic of supplier evaluation and how suppliers' ratings affect the delivery of products free of defects to construction projects has not received much attention by the IGLC community. This paper presents results of a study, which underscores the importance of conducting supplier evaluation as a means to assure quality products are delivered to construction projects. Findings show that suppliers with low ratings, or who are not evaluated, are assigned more hours of inspection, as are suppliers who subcontract portions of their work. This practice translates not only into additional budgets required to inspect suppliers, but also additional management-related costs.
\end{abstract}

Keywords: Lean construction, supplier evaluation, nonconformances, quality.

\section{INTRODUCTION}

The topic of supplier evaluation is usually discussed as part of materials management and procurement evaluations (Construction Industry Institute [CII] 1999), as well as studies related to risk analysis in construction projects (Monckza et al. 2016). Suppliers are usually evaluated prior to being hired to deliver a purchase order (PO) through the use of "formal supplier evaluation systems," and contractors are more likely to have these systems than owners (CII 1999). Despite having formal systems to evaluate suppliers, a recent study by CII RT308 revealed that contractors are evenly split $(54.4 \%$ yes vs. $45.6 \%$ no) when it comes to the use of prior supplier evaluation to make decisions about future purchases. Owners who participated in the same study were even less likely to use prior performance evaluations to base their decisions to award POs (Alves et al. 2016b). This current practice goes against Lean principles that promote the use of indicators and information to support a transparent management of value streams and

1 Associate Professor, J.R. Filanc Construction Engineering and Management Program, Dept. of Civil, Constr., and Env. Engineering, San Diego State University, USA, talves@mail.sdsu.edu

2 Graduate Research Assistant, Dept. of Civil, Constr., and Env. Engineering, San Diego State University, USA, panthildesai@gmail.com

3 Dean, Graduate School and International Education, University of Arkansas, Fayetteville, AR, USA, kneedy@uark.edu

4 Industrial Engineer, Former University of Arkansas student, Fayetteville, USA, ashleigh.hegwood@gmail.com

5 Director, Performance Excellence, MEI Technologies, Inc. (MEIT), Houston, TX, USA seanmusick@gmail.com 
working with suppliers to promote continuous improvement. Supplier ratings are collected but, unfortunately, not much is done with them. This paper discusses results of a recent survey with construction companies in the Engineering Procurement and Construction (EPC) industry. Hypotheses are developed and tested to verify the relationship between supplier ratings, inspection hours, and final product quality.

\section{LITERATURE REVIEW}

Suppliers play an important role in the literature on Lean practices throughout multiple phases of a product life-cycle, from the development of suppliers, through product design, manufacturing, and distribution. Liker's Toyota Way (2003) describes at least three principles that directly relate to the discussion presented in this paper: Principle 5: Build a culture of stopping to fix problems, to get quality right at the first time; Principle 17: Respect your extended network of partners and suppliers by challenging them and helping them improve; and, Principle 18: Go and See for yourself to thoroughly understand the situation (Genchi Genbutsu).

Liker's (2003) principles 5 and 18 are also supported by the discussion presented by Rother (2010, p.181), who stresses the importance of process improvement at Toyota and how it responds to process abnormalities: the responses to process abnormalities should be immediate; and, the response to process abnormalities should come from someone other than the production operators. The former statement underscores the importance of dealing with problems as soon as they happen so that adjustments can be made before any targets are missed and before the problems grow bigger. This suggests that a team leader should be appointed to help teams proactively resolve these problems.

Before becoming a preferred partner at Toyota, suppliers often work closely with the company for many years before they are ever awarded a PO. Toyota has high expectations for its suppliers and, during the years before the award of a PO, suppliers learn about these expectations and how they will work in practice (Liker 2003). The literature on supplier evaluation shows that suppliers who are frequently evaluated, receive feedback about their performance, and know what is expected from them perform better and are more committed to their clients as they can adjust their processes to match clients' requirements (Kannan and Tan 2002; Prahinski and Fan 2007). Moreover, Walsh et al.'s (2015) study in the EPC industry revealed that companies that communicate more often with suppliers, use supplier ratings, track indicators like cost and time spent on POs, and use suppliers with quality management systems tend to find nonconformances (NCs) early in the life of a PO, preventing these NCs from reaching construction projects.

In addition to these principles that can be used to support a healthy environment to respect and grow the capabilities of an extended network of suppliers, another principle outlined by Liker (2003) supports the discussion presented herein: Principle 1: Base your long-term management decisions on a long-term philosophy, even at the expense of short-term financial goals. The study presented in this paper illustrates how suppliers with low ratings are hired at the expense of product quality. This often happens because of low PO costs offered by these suppliers, and the practice adopted by some companies to compensate this deficiency is to assign additional inspection hours to a PO instead of working with suppliers to improve their capabilities. 


\section{RESEARCH METHOD}

This study was developed as part of the extension work of the research team 308 (RT308) funded by the Construction Industry Institute (CII) from 2015-2016. RT308 membership included academics (co-authors of this paper) and industry practitioners (owners, EPC contractors [co-author], and suppliers) referred to subject matter experts (SMEs) in this paper. As part of the team's goal to define ways for companies to determine the fabrication and inspection capabilities of suppliers, the team developed a survey (PO instrument), which was initially tested within the team, revised, and later distributed to the CII membership. The PO instrument was developed based on RT308's previous work (Walsh et al. 2015) and adapted to address one single material: shop fabricated piping. The SMEs suggested that the team should be able to collect data on this product which is present in virtually any project they developed, and in future efforts the PO instrument could be adapted to collect data for other materials so that fabrication and inspection capabilities can be defined for them as well.

The PO instrument, fully available at Alves et al. (2016b), contained 28 questions organized into four main parts: contact data from the respondent (to clarify any questions about the responses) and project demographics (name, type, dollar value, role of the respondent); basic data about the single PO being used in each survey (reference number, number of spools dollar value of the PO, inspection hours budgeted, location of supplier facility, and criticality level of the $\mathrm{PO}$ ); pre-award evaluation (level of inspection assigned, existence of supplier evaluation/reasons for doing or not doing so, pre-award supplier evaluation using criteria discussed later in this paper); and post-execution evaluation (inspection hours utilized, existence of subcontracting, final level of inspection, comparison between planned vs. actual hours of inspection, total number of pipe spools received for the PO, number of unplanned quality events, post -award supplier evaluation using criteria discussed later in this paper). The institutional review boards (IRBs) at San Diego State University and the University of Arkansas, Fayetteville approved the survey distribution and handling of data obtained, which also complied with CII guidelines for data collection and analysis.

\subsection{Hypotheses Testing}

RT308 developed the hypotheses outlined in Table 1 to investigate the relationship between certain practices and characteristics of the PO indicated by respondents. Only hypotheses related to supplier ratings and product quality are discussed in this paper. A full discussion of all hypotheses tested can be found in Alves et al. (2016b).

The Mann-Whitney (M-W) test, also known as Wilcox-Mann-Whitney test, was used to evaluate the hypotheses given that the data was not normally distributed. The M$\mathrm{W}$ test is considered a statistically powerful test among all non-parametric tests (Field 2012).

Data entries submitted through Qualtrics (an online survey platform) were reviewed and questions were cleared with respondents. The analysis was developed using IBM SPSS and data was organized and analyzed using Field's (2012) recommendations. The questions used to conduct the analysis are also shown in Table 1. 
Table 1: Hypotheses related to supplier evaluation and number of NCs

\begin{tabular}{|c|c|}
\hline Hypothesis & Source of date in new PO instrument \\
\hline $\begin{array}{c}\text { Hypothesis 2: A supplier with a higher } \\
\text { rating will have a higher } \mathrm{P}_{\text {fab }} \text { (fabrication } \\
\text { capability) and fewer inspection hours } \\
\text { budgeted. }\end{array}$ & $\begin{array}{l}\text { Q-10 Inspection hours budgeted; Q-24 } \\
\text { Post-execution evaluation. }\end{array}$ \\
\hline $\begin{array}{l}\text { Hypothesis } 4 \text { : More sub-suppliers } \\
\text { associated with a PO (Q-21) leads to a } \\
\text { lower } \mathrm{P}_{\mathrm{fab}} \text { and more inspection hours }\end{array}$ & $\begin{array}{c}\text { Q-21 Supplier subcontracting a portion of } \\
\text { the work for PO; Q-19 Inspection hours } \\
\text { utilized }\end{array}$ \\
\hline $\begin{array}{l}\text { Hypothesis } 6 \text { : Higher supplier ratings } \\
(\geq 4) \text { should result in lower number of } \\
\text { NCs at shop. }\end{array}$ & $\begin{array}{l}\text { Q-24 Post-execution evaluation; Q-27 } \\
\text { Number of unplanned quality events at } \\
\text { the shop. }\end{array}$ \\
\hline $\begin{array}{l}\text { Hypothesis 8: The number of inspection } \\
\text { hours will be higher on POs for which } \\
\text { the supplier was not evaluated. }\end{array}$ & $\begin{array}{l}\text { Q-10 Inspection hours budgeted; Q- } \\
14 \text { Did you perform a supplier } \\
\text { evaluation before the PO was issued? }\end{array}$ \\
\hline $\begin{array}{l}\text { Hypothesis 9: More inspection hours are } \\
\text { spent when the supplier's rating is low. }\end{array}$ & $\begin{array}{l}\text { Q-19 Inspection hours utilized; Q-24 Post- } \\
\text { execution evaluation. }\end{array}$ \\
\hline
\end{tabular}

\subsection{Supplier Evaluation Criteria}

After an analysis of supplier evaluation procedures provided by RT308 members, a list of items evaluated was compiled and presented for discussion in one of the team's meetings. The subject matter experts (SMEs) categorized the items identified into nine categories, which were later used in the PO instrument to assess supplier pre- and post-execution on a Likert scale from 1 to 5 (Alves et al. 2016a):

- Plant operations / Building and infrastructure - storage and shipping, structure for $\mathrm{QA} / \mathrm{QC}$ personnel and records, examination and testing, housekeeping, security.

- Manufacturing capability - machining capability, fabrication capability (including welding, coatings, etc.), capability to manufacture per user requirements, calibration records and procedures, non-destructive testing and inspection capability and quality, shop capacity.

- Experience and qualifications - geographical areas in which supplier is qualified to work, familiarity with codes specific to certain geographic regions, certifications (ASME, API, etc.), work history.

- Workforce - documented training of the workforce, craft types available at location, qualifications of the workforce, source of backup workers.

- Engineering capability - professional/technical specialties held in house, compliance with documents and specifications, cooperation, responsiveness of requests, and turnaround documents, robust document management system.

- Material control - QA/QC manual for material control, process for material substitution, material verification, prevention of counterfeit materials, material certification.

- Adherence to procedures and standards - adherence to codes and specifications, quality, legibility and completeness of documentation, non-conformance control, 
proper notification of inspection and hold points, Identification of parts traceability.

- Safety adherence and record - written safety, health and environmental program, compliance to local/governmental safety and environmental requirements, experience modification Ratio (EMR), total recordable incidence rate (TRIR).

- Handling of subcontractors/sub-suppliers - outsourced/subcontracted product/service control, procedure to check subcontractor compliance with quality requirements, documented evidence of compliance, auditing subcontractors, ability to schedule and expedite subcontractors/sub-suppliers.

\section{ANALYSIS OF RESULTS}

A total of 41 POs were received by RT308, however, not all submissions had answers to all questions, e.g., number of nonconformances at the site were not indicated, pre-award evaluation not available. This resulted in different numbers of POs being used to evaluate different questions. Only a few responses regarding pre-award supplier evaluation were submitted, however, most respondents had post-execution evaluations, which were used to analyze the hypotheses discussed in this paper. The team had originally hoped to evaluate differences between pre-award and post-execution, but due to the low number of data points for pre-award that was not possible. During both phases of RT308's project, respondents to both PO surveys indicated multiple reasons for not evaluating suppliers (Alves et al. 2016a, b) including: supplier had been evaluated by owner of the project, evaluations had been updated with post-execution, existence of approved list of suppliers did not require additional evaluation, the client had issued the $\mathrm{PO}$, and previous experience with the supplier.

\subsection{Demographics}

The data came from 10 companies representing 37 different projects. Out of that sample, owner companies submitted 10 POs (24\%) and contractors submitted 31 (76\%). One single company submitted 15 POs, and the authors understand that this is a limitation of this data set. The POs dollar values ranged from $\$ 255,000$ to $\$ 50,660,888$. The total dollar value of all submitted POs was $\$ 281,091,967$. About $63 \%$ of the POs submitted had a dollar value between $\$ 1$ million and $\$ 10$ million, $20 \%$ were between $\$ 100,000$ and $\$ 1$ million, and $17 \%$ of the POs were over $\$ 10$ million. The minimum number of spools in a single PO was 16 spools and the maximum number was 37,500 spools.

Among the 41 POs, about $90 \%$ of the POs were delivered by suppliers located in developed countries and $10 \%$ by suppliers in developing countries. For confidentiality reasons, the instrument did not collect data about the names of specific suppliers, only the location of the facility that manufactured the order was recorded. However, respondents indicated 19 specific cities, some of them appearing more than once, and others indicated only the country where the supplier's facility was located (e.g., USA). Additionally, in $32 \%$ of the 41 POs, the supplier had subcontracted a portion of the PO. Data reveal that subcontracting is a common practice even for commodities such as shop fabricated piping. The analysis of the POs submitted revealed that $47.5 \%$ of the POs ended up with an inspection level higher than originally budgeted, 35\% had a lower inspection level at the end, and only $17.5 \%$ had the inspection level to be equal to the budgeted level. The analysis revealed that inspection work was under planned for $14 \%$ of the POs submitted. 


\subsection{Supplier rating cut-off: high vs. low ratings}

Once the team started the analysis of the PO instrument data, a cut-off value of the 5point Likert scale had to be selected to categorize high versus low supplier evaluations. At first, the cut-off value of 4 was chosen for high rating, and suppliers with a rating equal or higher than 4 would be considered highly rated, whereas anything below that would be treated as low rating. To confirm this decision, a sensitivity analysis was carried out to investigate if a different cut-off number should be used in the analysis.

The analysis used the supplier ratings for post-execution evaluation and the number of NCs found for a same PO. Cut-off values of 3, 3.5, 4, and 4.5 were evaluated and outliers were addressed. To see this detailed sensitivity analysis refer to Hegwood (2016). The analysis revealed that moving the cut-off to a supplier rating of 3 or 3.5 would allow too many data points where the specific PO had a high number of NCs associated with the product. Conversely, a cut-off rating of 4.5 left only a few suppliers with a low number of NCs. The lower the cut-off rate, the higher the number of discrepancies linking the numbers of NCs and the supplier ratings, and the higher the number of suppliers who would receive a good rating with a high number of NCs when compared to other suppliers in the sample. Finally, the analysis suggested that the cut-off rate of 4 was appropriate as suppliers with ratings of 4 and above did not consistently display a high number of NCs when compared to suppliers getting lower scores.

\subsection{Analysis of Hypotheses}

Table 2 shows the findings related to the hypotheses testing conducted by the team. Results are organized to indicate what matters when supplier ratings are considered. It is worth noting that the data used in this discussion was not normalized by the cost of the PO or the number of spools in a PO. When the data is normalized, results change in some cases (that is, results might not be significant). Results were discussed with the team's SMEs and the non-normalized numbers presented herein where considered representative for this analysis. A full analysis can be found at Alves et al. (2016b).

The testing of Hypothesis 2 (a supplier with a higher rating will have a higher $P_{f a b}$ (fabrication capability) and fewer inspection hours budgeted) indicated that more inspection hours are budgeted when supplier ratings are low, that is lower than 4 $(\mathrm{p}=0.001$, highly significant). Similarly, Hypothesis 4 (more sub-suppliers associated with a PO leads to lower Pfab and more inspection hours) was also confirmed ( $\mathrm{p}=0.01$, significant) as more inspection hours are used when portions of a PO are subcontracted.

Hypothesis 6 (higher supplier ratings should results in lower number of NCs at the shop) was confirmed as well ( $\mathrm{p}=0.000$, highly significant) as more NCs are found at the shop when the supplier rating, as measured using the criteria presented above, is low (below 4). Hypothesis 8 (the number of inspection hours will be higher on POs for which the supplier was not evaluated) was confirmed $(\mathrm{p}=0.018)$ in that more inspection hours are budgeted when the supplier is not evaluated. Finally, Hypothesis 9 (more inspection hours are spent when the supplier's rating is low) was confirmed $(\mathrm{p}=0.000)$ as the analysis revealed that more inspection hours are spent when the supplier's rating is low (below 4).

The analysis presented underscores the importance of selecting suppliers with good evaluations, and, more importantly, developing suppliers to achieve higher ratings and meeting clients' demands and expectations. The analysis developed with the support of the team's SMEs indicated that suppliers with low ratings usually have the lowest cost and are perceived by procurement professionals to provide the best deal for their projects. 
This goes against the idea exposed in The Toyota Way's Principle 1: Base your longterm management decisions on a long-term philosophy, even at the expense of shortterm financial goals (Liker 2003). Also, suppliers who subcontract parts of their POs might display a low price tag at first, but costs add up when problems arise with their extended supply chain. The problem is, according to RT308's SMEs, they do not always know about subcontracting practices ahead of time.

Table 2: Findings RT308's project extension and practical implications

\begin{tabular}{|c|c|c|}
\hline Description & $\begin{array}{l}\text { Does it make } \\
\text { a difference? }\end{array}$ & How? Why? When? \\
\hline $\begin{array}{l}\text { Suppliers with low } \\
\text { ratings in evaluations. }\end{array}$ & Yes & $\begin{array}{l}\text { More inspection hours budgeted and more NCs are } \\
\text { found at the shop. This suggests that additional } \\
\text { money ends up being spent to assure quality when } \\
\text { these suppliers are selected. }\end{array}$ \\
\hline $\begin{array}{l}\text { Subcontracting, even } \\
\text { for portions of a } \\
\text { commodity like shop } \\
\text { fabricated piping, } \\
\text { result in more hours of } \\
\text { inspection budgeted. }\end{array}$ & Yes & $\begin{array}{l}\text { During the pre-award evaluations, subcontracting } \\
\text { should be factored in as something that will increase } \\
\text { the costs of surveillance and quality assurance. }\end{array}$ \\
\hline $\begin{array}{l}\text { Pre-award evaluation } \\
\text { of suppliers. }\end{array}$ & Yes & $\begin{array}{l}\text { More budgeted inspection hours are used when the } \\
\text { supplier is NOT evaluated. This finding adds to } \\
\text { RT308's previous findings in that both pre-award } \\
\text { and post-award evaluation matter and should be } \\
\text { used in continuous improvement efforts. }\end{array}$ \\
\hline
\end{tabular}

When suppliers are not evaluated, organizations are unclear regarding what to expect and this results in additional budgeted hours to assure quality. Previous RT308's findings indicated that companies often do not share potential feedback and ratings because of a fear of lawsuits (Walsh et al. 2015). Due to adversarial relationships found in the industry, often times suppliers and contractors do not receive the feedback they might have to share with one another, and lessons learned are not shared (Caldas et al. 2009). These attitudes do not help to build respect in these organizations extended networks of suppliers and it certainly does not help them improve.

Additionally, data on supplier evaluations and NCs are collected but not used to make decisions on new purchase orders or are erased as new POs are evaluated and included in companies' databases (Alves et al. 2016a). Companies could use this data to develop predictive analytics, based on machine learning algorithms, to inform their supplier selection processes and improve the quality of products they use in projects.

\section{CONCLUSIONS}

This paper presented the results of a study that investigated the link between supplier ratings and current industry practices, inspection hours, and nonconformances. EPC companies are missing opportunities to resolve problems as they appear on the shop floor, understanding the situation, and working to prevent new incidents. Data suggests that suppliers with low performance ratings and those that subcontract work likely require more inspection hours when they are awarded a PO due to the likelihood that 
more NCs are found at the shop. Instead of working with suppliers ahead of the PO execution to prevent these problems, organizations are just increasing their inspection effort, without necessarily addressing the root cause of problems. The number of POs assessed and the specific material considered limits this study's conclusions. Future studies might consider using a larger dataset, impact to safety performance, and different materials to validate and expand the results presented. Additional analyses of the current dataset are underway and will be reported by the authors in future publications.

\section{ACKNOWLEDGMENTS}

The authors are thankful for the financial support provided by the Construction Industry Institute (CII) and the countless hours of work spent on this project by RT308's team members. The paper reflects the opinions of the authors and not those of the CII.

\section{REFERENCES}

Alves, T.C.L., Needy, K.L., and Desai, P. (2016a). Achieving Zero Rework through Effective Supplier Quality Practices. The University of Texas at Austin. Research Report 308-1?.

Alves, T.C.L., Ravagui, K., Needy, K.L. (2016b). "Supplier Selection in EPC Projects: An Overview of the Process and its Main Activities.” ASCE, 2016 Construction Research Congress, University of Puerto Rico, Mayagüez, 10pp.

Caldas, C.H., Gibson Jr, G.E., Weerasooriya, R., and Yohe, A.M. (2009). "Identification of Effective Management Practices and Technologies for Lessons Learned Programs in the Construction Industry." ASCE, J. of Const. Engrg. and Mgmt., 135(6), 531-539

Construction Industry Institute (1999). Procurement and Materials Management: A Guide to Effective Project Execution.

Field, A. (2012). Discovering Statistics Using SPSS, 3rd Ed., Sage Publications, London.

Hegwood, A. (2016). Effective Supplier Quality Practices in the Construction Industry. Undergraduate honors thesis. University of Arkansas, College of Engineering. 59pp.

Kannan, V. R. and Tan, K.C. (2002). "Supplier Selection and Assessment: Their Impact on Business Performance.” The Journal of Supply Chain Mgmt., Fall 2002, 11-21

Liker, J. (2003). The Toyota Way: 14 Management Principles from the World's Greatest Manufacturer, McGraw-Hill, New York, 350pp.

Neuman, Y., Alves, T.C.L., Walsh, K.D., and Needy, K.L. (2015) "Quantitative Analysis of Supplier Quality Surveillance Practices in EPC Projects." Journal of Construction Engineering and Management, 141(11).

Monczka, R. M. Handfield, R. B., Giunipero, L. C. and Patterson, J.L. (2016). Purchasing and Supply Chain Management. $6^{\text {th }}$ ed. 858pp.

Prahinski, C. and Fan, Y. (2007). "Supplier Evaluations: The Role of Communication Quality." The Journal of Supply Chain Management, Summer 2007, 16-28

Rother, M. (2010). Toyota Kata. McGraw-Hill, New York, NY, 306pp.

Walsh, K.D., Needy, K.L., Alves, T.C.L., Neuman, Y., can, R.Y., Ahmad, S. (2015). Achieving Zero Rework through Effective Supplier Quality Practices. Construction Industry Institute, The University of Texas at Austin. Resesearch Report 308-11. 